\title{
Mean Atrial Rate by Electrocardiogram
}

National Cancer Institute

\section{Source}

National Cancer Institute. Mean Atrial Rate by Electrocardiogram. NCI Thesaurus. Code C119256.

The calculated average rate of atrial depolarization ( $P$ waves) as measured and recorded by an electrocardiograph during a specified period of time, and which is usually expressed in beats per minute. 